\title{
Confinement-Controlled, Either syn- or anti-Selective Catalytic Asymmetric Mukaiyama Aldolizations of Propionaldehyde Enolsilanes
}

Tynchtyk Amatov, Nobuya Tsuji, Rajat Maji, Lucas Schreyer, Hui Zhou, Markus Leutzsch, and Benjamin List*

Cite This: J. Am. Chem. Soc. 2021, 143, 14475-14481

Read Online

ABSTRACT: Protected aldols (i.e., true aldols derived from aldehydes) with either syn- or anti- stereochemistry are versatile intermediates in many oligopropionate syntheses. Traditional stereoselective approaches to such aldols typically require several nonstrategic operations. Here we report two highly enantioselective and diastereoselective catalytic Mukaiyama aldol reactions of the TBS- or TES- enolsilanes of propionaldehyde with aromatic aldehydes. Our reactions directly deliver valuable silyl protected propionaldehyde aldols in a catalyst controlled manner, either as syn- or anti-isomer. We have identified a privileged IDPi catalyst motif that is tailored for controlling these aldolizations with exceptional selectivities. We demonstrate how a single atom modification in the inner core of the IDPi catalyst, replacing a $\mathrm{CF}_{3}$-group with a $\mathrm{CF}_{2} \mathrm{H}$-group, leads to a dramatic switch in enantiofacial differentiation of the aldehyde. The origin of this remarkable effect was attributed to tightening of the catalytic cavity via unconventional $\mathrm{C}-\mathrm{H}$ hydrogen bonding of the $\mathrm{CF}_{2} \mathrm{H}$ group.

$\mathrm{P}$ olyketides are pharmaceutically important secondary metabolites. ${ }^{1}$ Erythromycin is a prototypical example, which as a synthetic target was declared by Woodward as "hopelessly complex ...in view of its plethora of asymmetric centers". ${ }^{2}$ This statement encouraged the beginning of several decades of intense and highly innovative method development in acyclic stereocontrol. Generations of chemists have contributed approaches to overcoming the synthetic challenges posed by oligopropionates, typically bearing linear stereopolyads with alternating methyl and hydroxyl groups. ${ }^{3}$ Nonetheless, only few truly reliable methods have found general utility in numerous syntheses of complex oligopropionates. ${ }^{4}$ Widely used approaches, based on chiral auxiliaries, rely on diastereoselective asymmetric propionate aldolizations or crotylation reactions (Figure 1)., ${ }^{5,6}$ Very often, both approaches converge after several steps: following the critical diastereoselective $\mathrm{C}-\mathrm{C}$ bond-formation, protecting group installation and redox manipulations lead to stable protected aldol intermediates of a general structure I, which are ideal for downstream functionalization to construct various polyketide motifs. Catalytic asymmetric crotylation methods developed more recently by Krische et al. provide an attractive alternative but feature a moderate step-economy when protected aldols of type I are needed. ${ }^{7}$ Direct stereoselective cross-aldol reactions of aldehydes have also been described, but an additional protection step is often unavoidable. ${ }^{8}$ A truly practical approach, from a total synthesis chemist's perspective, would directly deliver the protected aldols in a predictable catalytic manner, with full control over diastereoselectivity and enantioselectivity. In this regard, arguably the most useful variant of the Mukaiyama aldol reaction, ${ }^{9}$ the aldolization of propionaldehyde-derived enolsilanes with aldehydes, has

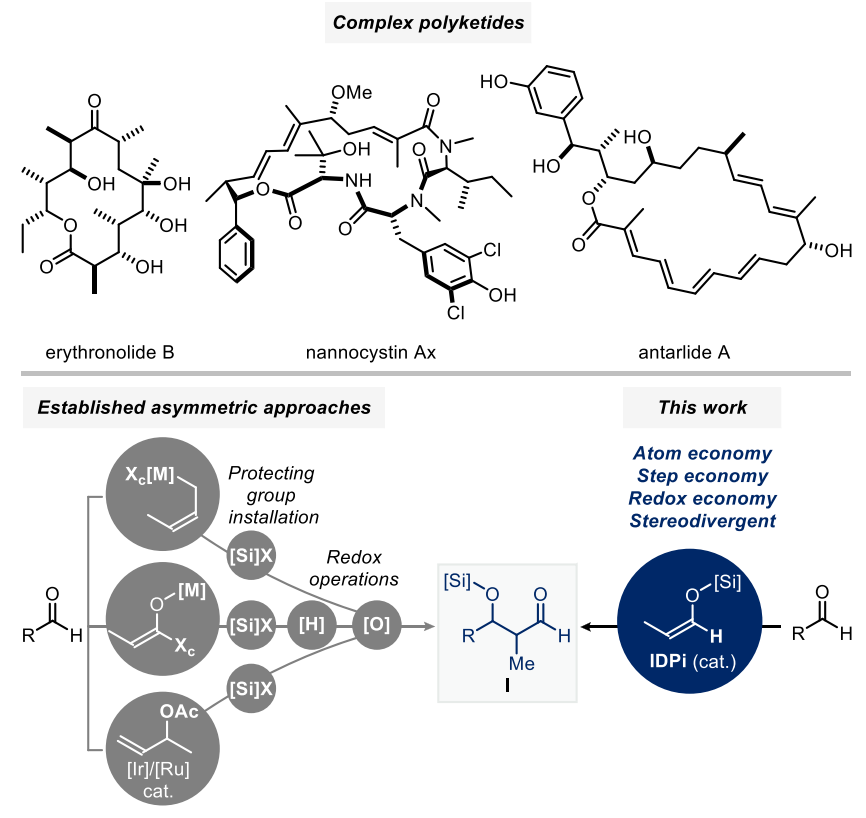

Figure 1. Complex bioactive polyketides. Established approaches to protected aldols I vs our single-step, stereodivergent method.

Received: July 19, 2021

Published: August 26, 2021 
remained elusive. In addition to directly delivering the protected aldols, such a reaction would favorably meet all of the metrics used to evaluate synthetic methods, such as atom-, ${ }^{10}$ redox-, ${ }^{11}$ and especially step-economy. ${ }^{12}$

Yamamoto reported nonenantioselective examples using the bulky tris(trimethylsilyl)silyl (TTMSS, supersilyl) group to control selectivity toward single addition of aldehyde-derived enolsilanes. ${ }^{13}$ The first diastereo- and enantioselective examples by Denmark utilized trichlorosilyl enolsilanes under Lewis base catalysis. ${ }^{14}$ This approach is poorly atom-economic, as the silyl group is not retained in the final product and several steps are required to obtain aldols suitable for chain elongations. Kanai and Matsunaga reported an asymmetric $\mathrm{Cu}$-catalyzed aldolization using in situ generated boron enolates of propionaldehyde, which gives mainly syn-aldols. ${ }^{15}$ Although up to quadruple aldolizations were achieved, the existence of unprotected oligoaldols in various cyclic hemiacetal forms limits their selective elaboration to useful oligopropionate motifs. Recently we reported the first, highly enantioselective Mukaiyama cross-aldol reaction with simple triethylsilyl (TES) and tert-butyldimethylsilyl (TBS) enolsilanes of acetaldehyde and aliphatic and aromatic aldehydes using confined and strongly acidic imidodiphosphorimidate (IDPi) catalysts developed here. ${ }^{16}$ Enzyme-like discrimination of the small substrate aldehyde over the larger product aldehyde is believed to be the origin of single aldolization without oligomerization. ${ }^{17}$ From such a vantage point, exploitation of the unique reactivity of IDPi catalysts in the Mukaiyama cross-aldol reaction with propionaldehyde-derived enolsilanes would be even more valuable as it generates two (vicinal) stereogenic centers simultaneously, which are present in many bioactive polyketides (Figure 1). ${ }^{18}$ We envisioned developing a fully stereodivergent method giving access to all four stereoisomers. ${ }^{19}$ Herein, we report that the IDPi family of catalysts provides a powerful solution to this long-standing goal. $^{20}$

Our investigations commenced with an exploration of different IDPi catalysts in the aldolization of benzaldehyde 1 with $(E)$-enolsilanes $\mathbf{2 a}-\mathbf{b}$ or $(Z)$-enolsilanes $\mathbf{4 a - c}$ (Table 1 ). At the onset we found that the diastereoselectivity was dependent on the nucleophile geometry, with $(E)$-enolsilanes providing syn-aldols and $(Z)$-enolsilanes giving anti-aldols, with varying degrees of diastereoselectivity, depending on the silyl group and the catalyst. IDPi 6 , which was a preferred catalyst in our acetaldehyde-derived enolsilane additions, was tested in the reaction of $(E)$-enolsilane $2 \mathrm{a}$ with benzaldehyde at $-20^{\circ} \mathrm{C}$. Single aldolization product 3 was indeed formed in high yield, excellent diastereoselectivity (d.r. 97.5:2.5) in favor of the synaldol 3a $([\mathrm{Si}]=\mathrm{TES})$, and with a promising enantiomeric ratio (e.r.) of 10.5:89.5 (Table 1A, entry 1). Given that fluorenesubstituted IDPi catalysts were especially privileged in our recent silylium-ion asymmetric counteranion-directed catalysis $(\mathrm{Si} \text {-ACDC })^{21}$ methodologies, ${ }^{22 \mathrm{a}-\mathrm{d}}$ we turned our attention to catalysts $\mathbf{7 a - d}$ (and $\mathbf{S 8} \mathbf{a}-\mathbf{c}$ in the Supporting Information). Indeed, these IDPis emerged as preferred catalysts for our reactions. Spirocyclobutane-substituted IDPi 7a markedly stood out in terms of enantioselectivity, providing aldol 3a with a 95.5:4.5 e.r. (Table 1A, entry 2). Modification of the inner core of the IDPi from the Tf-group to a Nf-group further increased diastereoselectivity and enantioselectivity. Lowering the temperature to $-40{ }^{\circ} \mathrm{C}$ led to a d.r. of 99:1 and a 98:2 e.r. (Table 1A, entry 5). Variation of the silyl group was welltolerated when the TBS-enolsilane $\mathbf{2} \mathbf{b}$ was used instead of the
Table 1. Reaction Development

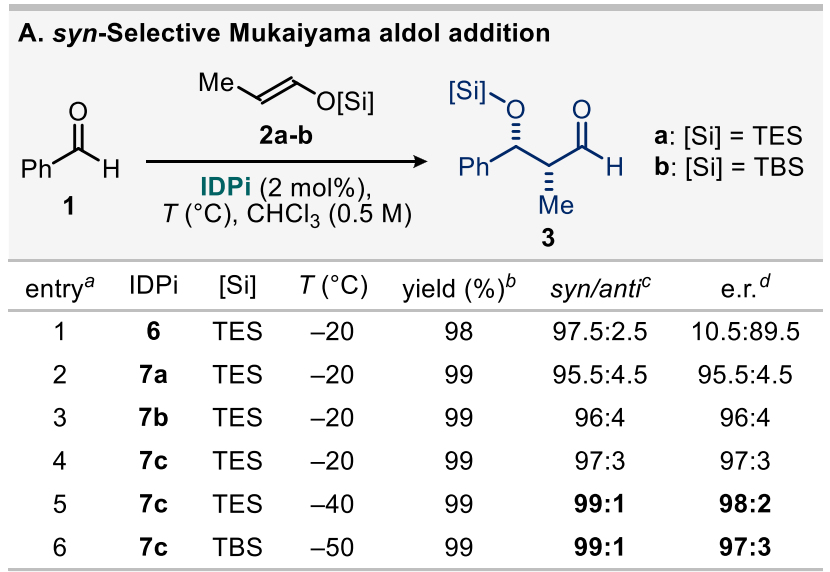

B. anti-Selective Mukaiyama aldol addition

\begin{tabular}{|c|c|c|c|c|c|c|}
\hline O & & C), $\mathrm{CH}$ & $\begin{array}{l}\text { 4a-c } \\
\text { nol\%), } \\
\mathrm{I}_{3}(0.5 \mathrm{M}\end{array}$ & {$[\mathrm{Si}]_{\mathrm{O}}$} & & $\begin{array}{l}\mathrm{Si}]=\mathrm{TES} \\
\mathrm{Sij}=\mathrm{TBS} \\
\mathrm{Si}]=\mathrm{TIPS}\end{array}$ \\
\hline entry ${ }^{a}$ & IDPi & [Si] & $T\left({ }^{\circ} \mathrm{C}\right)$ & yield $(\%)^{b}$ & anti/syn ${ }^{c}$ & e.r. ${ }^{d}$ \\
\hline 1 & $7 a$ & TES & -60 & 99 & $86: 14$ & $75: 25$ \\
\hline 2 & $7 a$ & TBS & -60 & 99 & $94: 6$ & $89: 11$ \\
\hline 3 & $7 a$ & TIPS & -60 & 99 & $90: 10$ & $83: 17$ \\
\hline 4 & $7 b$ & TES & -60 & 96 & $63: 37$ & $39: 61$ \\
\hline 5 & $7 c$ & TES & -60 & 84 & $62: 38$ & $38: 62$ \\
\hline 6 & $7 d$ & TES & -60 & 99 & $96: 4$ & $87: 13$ \\
\hline 7 & $7 d$ & TBS & -60 & 99 & $99: 1$ & $97.5: 2.5$ \\
\hline 8 & $7 d^{e}$ & TBS & -78 & 99 & $>99: 1$ & 98:2 \\
\hline
\end{tabular}
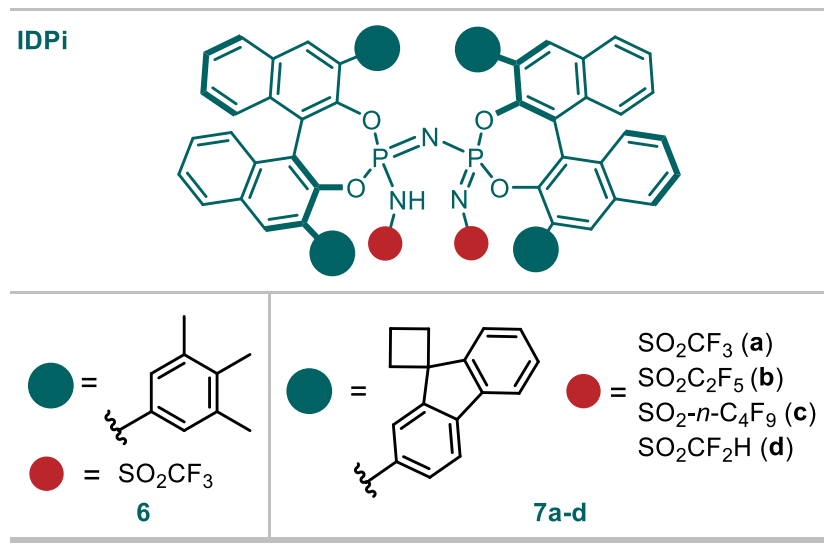

${ }^{a}$ Reactions were conducted with benzaldehyde 1 ( $\left.0.1 \mathrm{mmol}\right)$, enolsilanes $2 \mathbf{a}-\mathbf{b}$ or $4 \mathbf{a}-\mathbf{c}$ (1.2 equiv), and IDPi ( $2 \mathrm{~mol} \%)$ for $16-24 \mathrm{~h}$ at the indicated temperature. ${ }^{b}$ Determined by ${ }^{1} \mathrm{H}$ NMR spectroscopy. ${ }^{c}$ Determined by crude ${ }^{1} \mathrm{H}$ NMR analysis. ${ }^{d}$ The e.r. was determined by HPLC. ${ }^{e}$ At $-78{ }^{\circ} \mathrm{C}$ using a $5: 4 \mathrm{CHCl}_{3} / n$-hexane mixture. TES, triethylsilyl; TIPS, triisopropylsilyl; TBS, tertbutyldimethylsilyl. See the Supporting Information for determination of the absolute configuration.

TES-enolsilane 2a (Table 1A, entry 6). An opposite trend was observed in the anti-selective Mukaiyama aldol addition of $(Z)$-enolsilanes (Table 1B). Both the size of the perfluorinated sulfonamide in the inner core of IDPi and the silyl group had tremendous effects on the selectivity. Longer perfluorinated groups gave poorer d.r. and e.r. At $-60{ }^{\circ} \mathrm{C}$, the addition of 
Table 2. Substrate Scope for the syn- and anti-Mukaiyama Aldol Additions ${ }^{a}$

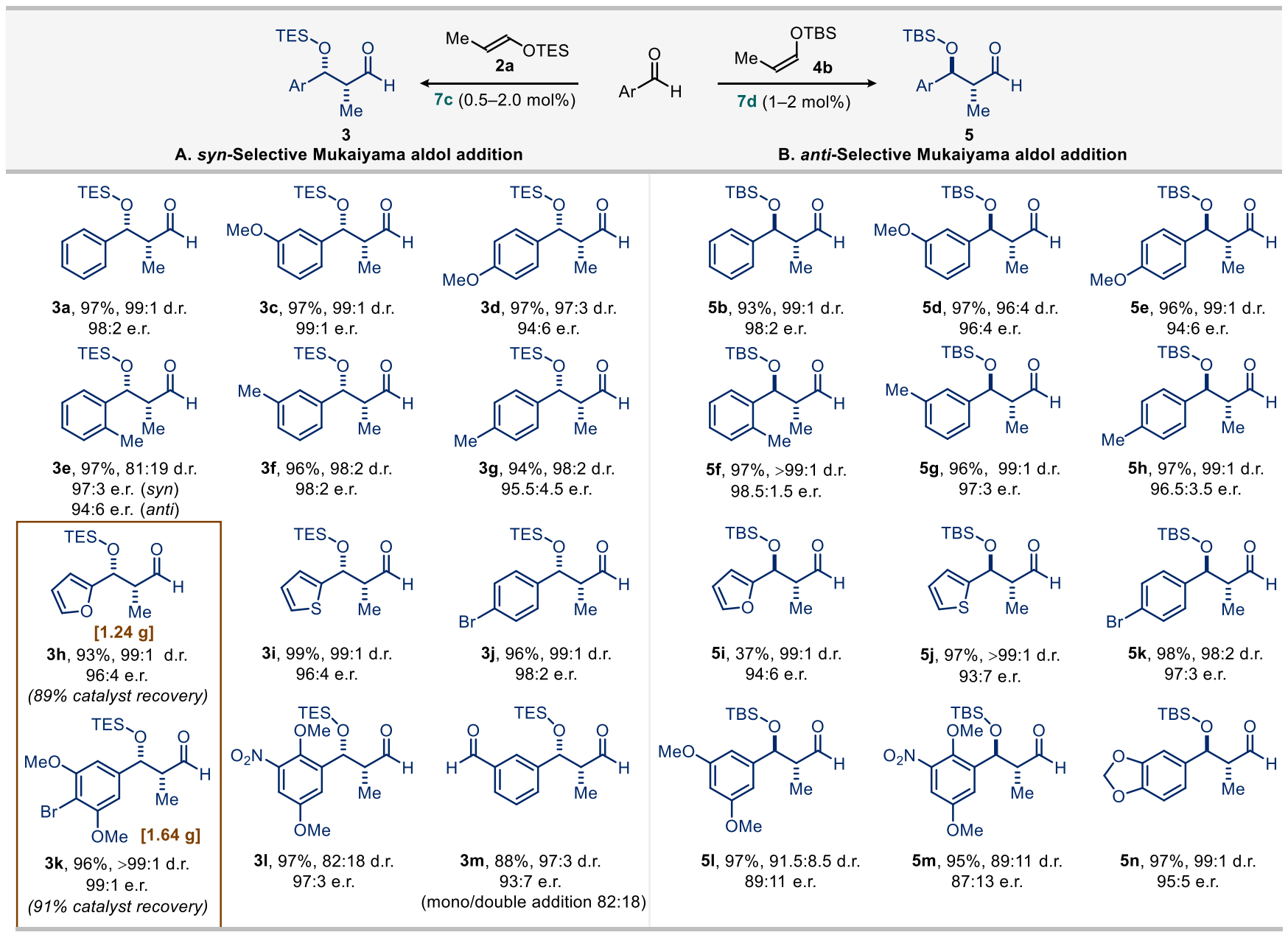

${ }^{a}$ Reaction scale: $0.2-5 \mathrm{mmol}$. See the Supporting Information for full reaction conditions and the determination of e.r.

(Z)-enolsilane 4a $([\mathrm{Si}]=\mathrm{TES})$ to benzaldehyde proceeded with modest d.r. and e.r. using catalysts $7 \mathbf{b}$ and $7 \mathbf{c}$, which performed exceptionally well previously in the syn-aldolization (Table 1B, entries 4-5). In contrast, IDPi $7 \mathrm{a}$ with the shortest trifluoromethylsulfonamide core performed far better, but to our surprise, with inverted benzaldehyde enantiofacial preference. Among $(Z)$-enolsilanes $\mathbf{4 a - 4} \mathbf{c}$ with different silyl-groups (Table 1B, entries $1-3$ ), enolsilane $4 \mathbf{b}$ with the TBS-group performed best, albeit only in 89:11 e.r. Hypothesizing that replacing one of the $\mathrm{F}$ atoms in the $\mathrm{CF}_{3}$-group to an $\mathrm{H}$ atom may help in positively influencing the selectivity without introducing significant steric changes, ${ }^{23}$ IDPi $7 \mathbf{d}$ containing a $\mathrm{CF}_{2} \mathrm{H}$-group was designed and synthesized. Specifically, we envisioned that $\mathrm{CF}_{2} \mathrm{H} \cdots$ heteroatom interactions could lead to a modulation of the active site of the IDPi catalyst. ${ }^{24}$ Strikingly, the single-atom modification of the inner core of the catalyst, replacing the $\mathrm{CF}_{3}$-groups with $\mathrm{CF}_{2} \mathrm{H}$-groups, indeed resulted in a spectacular enhancement of both the d.r. (99:1) and e.r. (98:2) in the addition of enolsilane $\mathbf{4 b}$ (Table 1B, entries 7 and 8).

With these results in hand, the scope of our syn-selective Mukaiyama aldol reaction with various aromatic aldehydes was explored, using catalyst 7c (Table 2A). Aromatic aldehydes with $o$-, $m$-, and $p$-substituents and heteroaromatic aldehydes $(\mathbf{3} \mathbf{a}-\mathbf{3} \mathbf{j})$ gave the corresponding products in excellent yields and stereoselectivity. Multisubstituted aromatic aldehydes provided products $3 \mathbf{k}-3 \mathbf{m}$, which contain substructures of complex polyketides. ${ }^{25,26}$ The catalyst loading could be reduced to $0.5 \mathrm{~mol} \%$ without compromising the reaction time and stereoselectivity as shown with the gram scale synthesis of aldols $3 \mathbf{h}$ and $3 \mathbf{k}$. A diastereoselective and enantioselective single aldolization of a dialdehyde substrate gave product $3 \mathrm{~m}$.

Essentially the same set of aromatic aldehydes performed equally well in our anti-aldolization process furnishing products $\mathbf{5 b}-\mathbf{k}$ and $\mathbf{5 m}$ (Table 2B). Electron-rich aromatic aldehydes also delivered anti-aldols $\mathbf{5 l}$ and $\mathbf{5 n}$ with good diastereoselectivity and enantioselectivity. Only furfural gave somewhat lower yield of product $\mathbf{5 i}$.

Furthermore, butyraldehyde-derived enolsilanes 8 and 9 also readily reacted to either syn- or anti-products 10 and 11 (Scheme 1A). Moreover, both enantiomers of our IDPi catalysts enabled access to all four possible stereoisomers of aldols as shown in Scheme 1B.

Our stereodivergent aldolization method is especially valuable in the context of the rapid generation of complex polyketide motifs (Scheme 1C). For example, when syn-aldol $3 \mathrm{~h}$ was subjected to a follow-up propionate aldolization using in situ generated chiral boron enolates $12,{ }^{27}$ either the all-synstereotetrad 13 or its syn, anti, syn stereoisomer 14 were obtained as single diastereomers. The structure of the polyketide-like molecule $\mathbf{1 3}$ was unambiguously confirmed by 
Scheme 1. Further Applications of the Diastereoselective and Enantioselective Aldol Reactions

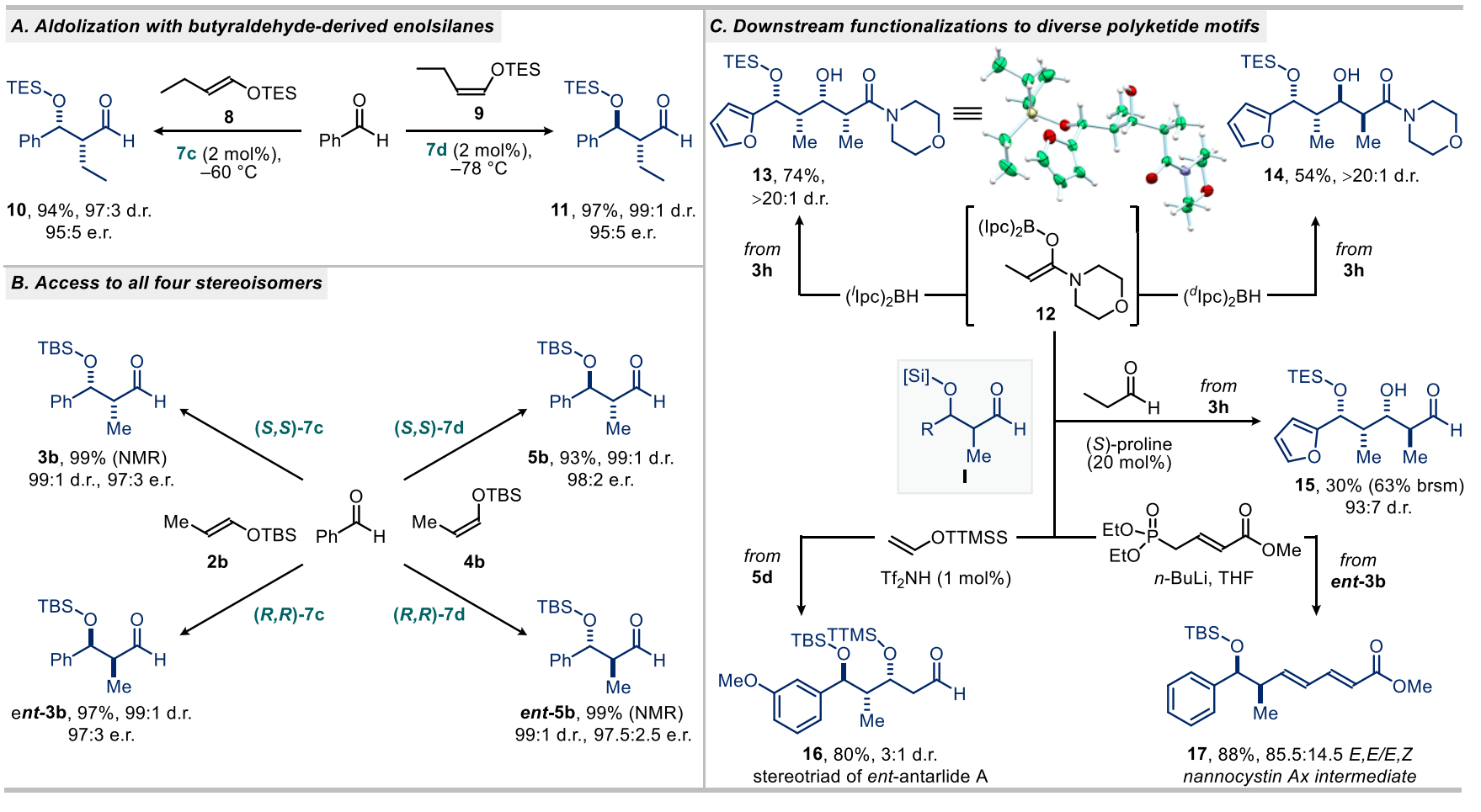

A. Catalysis with $\mathrm{Tf}_{2} \mathrm{NH}$<smiles>Cc1ccc(C=O)cc1</smiles>

$$
\underset{-40{ }^{\circ} \mathrm{C}, \mathrm{CHCl}_{3}(0.5 \mathrm{M})}{\stackrel{\text { 2a (1.2 equiv. })}{\longrightarrow}}
$$

B. Control experiment rules out matched/mismatched scenario

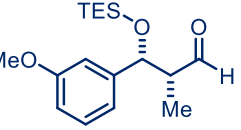

$$
\begin{aligned}
& \underset{\text { 2a }(1.2 \text { equiv. })}{\underset{(R, R)-7 \mathrm{c}(2 \mathrm{~mol} \%)}{-40,{ }^{\circ} \mathrm{C}, \mathrm{CHCl}_{3}(0.5 \mathrm{M})}}
\end{aligned}
$$

$3 c$
C. Acetaldehyde enolsilane additions and the origin of switch in enantioselectivity

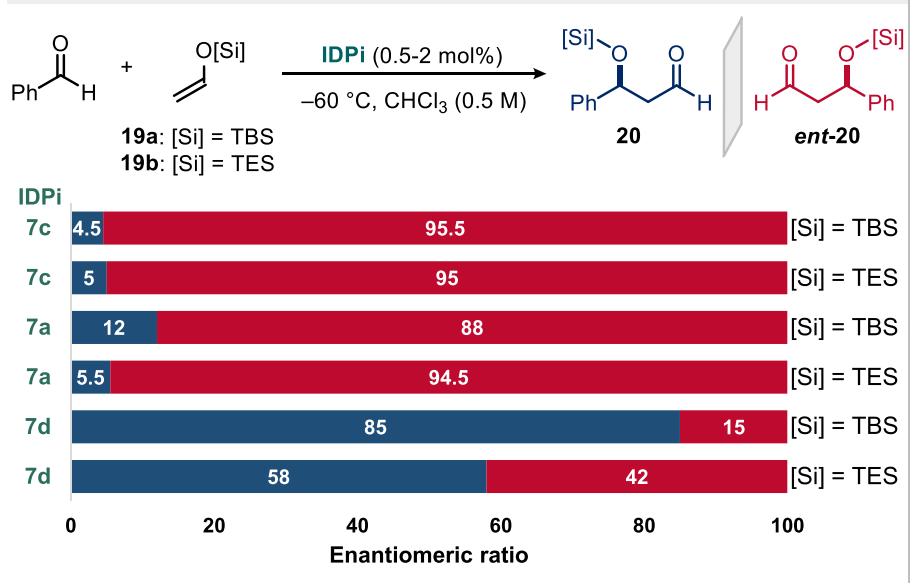

D. Transition state structures leading to $3 a$ and $5 b$ interactions<smiles>COc1cccc([C@H](OC#[SH])[C@H](C)C(OSC)C(C)C=O)c1</smiles>

$18(<10 \%)$

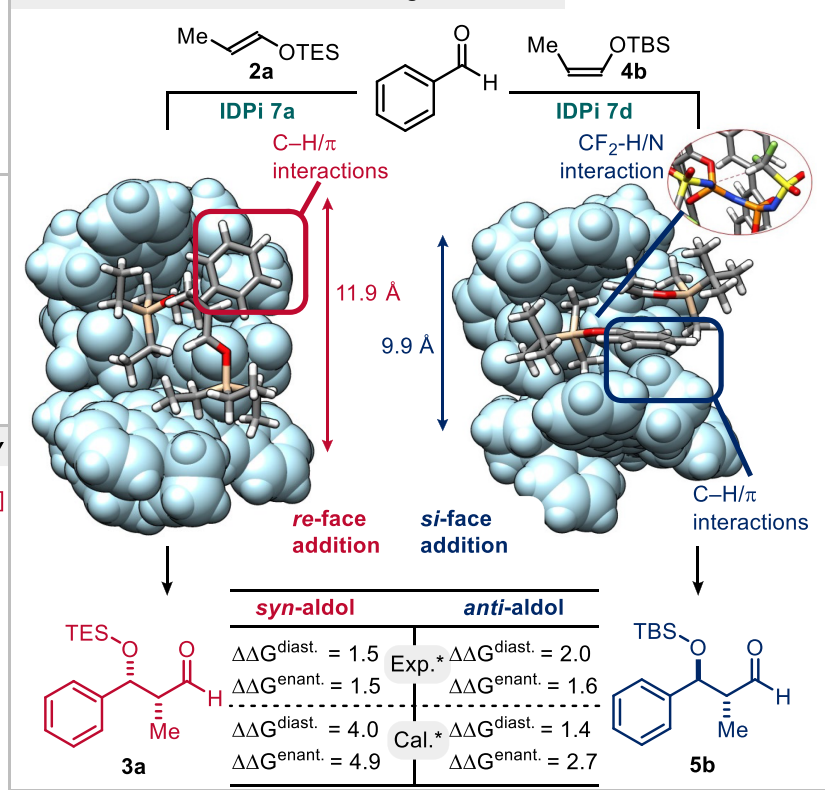

E. $\mathrm{C}-\mathrm{H}$ hydrogen bondings tighten the catalytic pocket

$103.7^{\circ}$

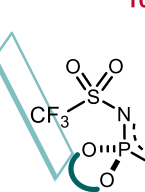

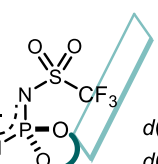

$d\left(\mathrm{CF}_{2} \mathrm{H} \cdots \mathrm{N}\right)=2.506 \AA$ $d\left(\mathrm{CF}_{2} \mathrm{H} \cdots \mathrm{O}\right)=2.755 \AA$

Figure 2. Mechanistic studies. (A-C) Control experiments. (D) Computed transition-state structures of major enantiomer of 3a (syn-selective addition) with $\mathbf{7 a}$ (left) and $\mathbf{5 b}$ (anti-selective addition) with 7d (right) at B3LYP-D3(BJ)/def2TZVP+CPCM(Chloroform)//ONIOM(PBE-D3/ 6-31G(d):PBE-D3/3-21G) level of theory. Distances between centroids of the two inner spirocyclobutyl-2-fluorenyl groups are shown. *Energies in $\mathrm{kcal} / \mathrm{mol}$ (see the Supporting Information for details). (E) Effect of $\mathrm{C}-\mathrm{H}$ hydrogen bondings on the cavity size. Angles represent centroids of the two inner spirocyclobutyl-2-fluorenyl groups and the central nitrogen. 
X-ray crystallography. Alternatively, iterative aldolization using the proline-catalyzed cross-aldol addition with propionaldehyde delivered the syn, syn, anti-stereotetrad 15 with excellent diastereoselectivity. Further, anti-aldol $\mathbf{5 d}$ was converted to a fully protected double aldol adduct $\mathbf{1 6}$, containing the key anti, syn-stereotriad of antarlide $\mathrm{A},{ }^{28}$ when our method was coupled with Yamamoto's supersilyl enolate technology. Stereotriad 16 is fully suited for further aldol addition toward antarlides. 1,3Dienyl-6-oxy polyketide motif 17 , an intermediate from a reported total synthesis of nannocystin Ax, was also obtained in only two steps starting from benzaldehyde (via ent-3b). The previous synthesis of $\mathbf{1 7}$ involved five steps, including an Evans-aldolization. ${ }^{29}$ It is noteworthy that all of the polyketide motives 13-17 were obtained in just two steps from commercially available aldehydes such as furfural, $m$ anisaldehyde, and benzaldehyde.

To gain insight into the mechanism of our stereoselective aldol additions, experimental and computational studies were performed. Experiments were directed at probing aspects of our aldol reactions such as the origin of single aldolization and the unexpected change of facial selectivity during antialdolization using IDPi 7d. Initially, we confirmed that our IDPi catalysts were indeed unique in promoting the single aldolization of propionaldehyde enolsilanes: the well-established Mukaiyama aldol addition catalyst triflimide did not give even a trace of the desired single aldolization products because of complete enolsilane oligomerization (Figure 2A, see the Supporting Information, Figure S2 for details). syn-Aldol 3c, which was obtained using IDPi $(S, S)-7 \mathrm{c}$ at $-40^{\circ} \mathrm{C}$, underwent less than $10 \%$ conversion under the same conditions using the opposite enantiomer of the catalyst $(R, R)-7 \mathbf{c}$, excluding a potential matched-mismatched scenario (Figure $2 B$ ). The change in facial selectivity of aldehyde attack upon switching from the $n-\mathrm{C}_{4} \mathrm{~F}_{9}$ - and $\mathrm{CF}_{3}$-groups to the $\mathrm{CF}_{2} \mathrm{H}$-group was also manifested when simple acetaldehyde-derived enolsilanes 19ab were used (Figure 2C). With catalysts $7 \mathbf{a}$ and $7 \mathbf{c}$, acetaldehyde-derived enolsilane additions to benzaldehyde proceeded with $r$-selectivity, giving ent-20 irrespective of the silyl groups. In contrast, IDPi $7 d$, having a difluoromethanesulfonyl group in the core, reacted with si-selectivity.

In order to probe the origin of stereoselectivity and the switch of enantiofacial selectivity, an extensive DFT study was conducted for both syn- and anti-selective additions with IDPis $7 \mathbf{a}$ and $7 \mathbf{d}$. Computed e.r.s and d.r.s were in good agreement with experimental observations in both cases (Figure 2D; see the Supporting Information, Figures S6-S10 for more details). When the optimized major transition-state structures of synand anti-selective aldolizations are compared, one of the most prominent differences appears to be the catalyst pocket size. ${ }^{30}$ While catalyst $7 \mathrm{a}$ with $\mathrm{CF}_{3}$-cores has a relatively open cavity, the $\mathrm{CF}_{2} \mathrm{H}$-groups in catalyst $\mathbf{7 d}$ engage in intramolecular hydrogen bonding interactions resulting in a more compact catalytic pocket (Figure $2 \mathrm{D}$ and $2 \mathrm{E}$ ). Accordingly, for the synselective addition with $\mathbf{7 a}$, the bulky $(E)$-enolsilane $\mathbf{2}$ a bearing a smaller TES group would approach from the less hindered $r e-$ face (Figure 2B, left). In contrast, for the case of anti-selective addition with $\mathbf{7 d}$, the sterically less hindered $(Z)$-enolsilane $\mathbf{4 b}$, with a slightly bulkier TBS group, provides a perfect fit into the narrower cavity, resulting in the complete switch of the facial selectivity (Figure 2D, right). The outcome of the acetaldehyde-derived enolsilane additions using catalysts 7 a and $\mathbf{7 d}$ is also in good agreement with this model (Figures 2C, S12, and S13).
Additionally, our study has identified the involvement of $\mathrm{CH} / \pi$ interactions, indicated in Figure $2 \mathrm{D},{ }^{31}$ between the spirocyclic methylene groups of the catalyst counteranion and the aromatic ring of the aldehyde substrate, which contribute to the high enantioselectivities in both transition states. ${ }^{32}$ This is in agreement with our experimental observations, showing a strong effect of the spirocycle on the enantioselectivity (Figure S1).

Our highly stereoselective Mukaiyama aldol additions of propionaldehyde enolsilanes give access to all stereoisomers of the stable and versatile protected aldols in a predictable manner and can be used in rapid syntheses of complex polyketide motifs. Ultimately, our approach could aid in streamlining the synthesis of complex oligopropionates. We also uncovered an unusual enantioreversal effect by modifying a $\mathrm{CF}_{3}$-group to a $\mathrm{CF}_{2} \mathrm{H}$-group. The origin of stereoselectivities and enantiofacial switch was rationalized through computational studies, revealing the cooperation of $\mathrm{C}-\mathrm{H}$ hydrogen bonds and $\mathrm{CH} / \pi$ interactions to govern catalyst structure and transition states.

\section{ASSOCIATED CONTENT}

\section{SI Supporting Information}

The Supporting Information is available free of charge at https://pubs.acs.org/doi/10.1021/jacs.1c07447.

Experimental details and analytical data for all new compounds (PDF)

\section{Accession Codes}

CCDC 2097850-2097853 contain the supplementary crystallographic data for this paper. These data can be obtained free of charge via www.ccdc.cam.ac.uk/data_request/cif, or by emailing data_request@ccdc.cam.ac.uk, or by contacting The Cambridge Crystallographic Data Centre, 12 Union Road, Cambridge CB2 1EZ, UK; fax: +44 1223336033.

\section{AUTHOR INFORMATION}

\section{Corresponding Author}

Benjamin List - Max-Planck-Institut für Kohlenforschung, D45470 Mülheim an der Ruhr, Germany; Institute for Chemical Reaction Design and Discovery (WPI-ICReDD), Hokkaido University, Sapporo 001-0021, Japan; ○ orcid.org/0000-0002-9804-599X; Email: list@ kofo.mpg.de

\section{Authors}

Tynchtyk Amatov - Max-Planck-Institut für Kohlenforschung, D-45470 Mülheim an der Ruhr, Germany; (1) orcid.org/0000-0002-6404-1253

Nobuya Tsuji - Institute for Chemical Reaction Design and Discovery (WPI-ICReDD), Hokkaido University, Sapporo 001-0021, Japan

Rajat Maji - Max-Planck-Institut für Kohlenforschung, D-

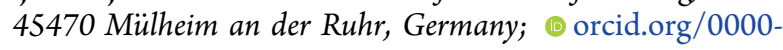
0003-2614-1795

Lucas Schreyer - Max-Planck-Institut für Kohlenforschung, D-45470 Mülheim an der Ruhr, Germany

Hui Zhou - Max-Planck-Institut für Kohlenforschung, D45470 Mülheim an der Ruhr, Germany

Markus Leutzsch - Max-Planck-Institut für Kohlenforschung, D-45470 Mülheim an der Ruhr, Germany; (1) orcid.org/ 0000-0001-8171-9399

Complete contact information is available at: 
https://pubs.acs.org/10.1021/jacs.1c07447

\section{Funding}

Open access funded by Max Planck Society.

\section{Notes}

The authors declare the following competing financial interest(s): A patent on the general catalyst class and its asymmetric catalysis has been filed.

\section{ACKNOWLEDGMENTS}

The authors acknowledge generous support from the Deutsche Forschungsgemeinschaft (DFG, German Research Foundation Leibniz Award to B.L.) and under Germany's Excellence Strategy (EXC 2033-390677874-RESOLV), the European Research Council (ERC, European Union's Horizon 2020 research and innovation program " $\mathrm{C}-\mathrm{H}$ Acids for Organic Synthesis, CHAOS” Advanced Grant Agreement No. 694228), and the Horizon 2020 Marie Sklodowska-Curie Postdoctoral Fellowship (to R.M., Grant Agreement No. 897130). The authors thank Benjamin Mitschke for his help with figures and several members of the group for our internal crowd reviewing. We also thank the technicians of our group and the members of our NMR, MS, X-ray, and chromatography groups for their excellent service. This work was also financially supported by the Institute for Chemical Reaction Design and Discovery (ICReDD), which was established by the World Premier International Research Initiative (WPI), MEXT, Japan, and by JSPS KAKENHI Grants $21 \mathrm{H} 01925$ and 20K22515.

\section{REFERENCES}

(1) Walsh, C. T. Polyketide and nonribosomal peptide antibiotics: modularity and versatility. Science 2004, 303, 1805-1810.

(2) Woodward, R. B. In Perspectives in Organic Chemistry; Todd, A., Ed.; Wiley-Interscience: New York, 1956; p 160.

(3) (a) Heathcock, C. H. Acyclic Stereocontrol through the aldol condensation. Science 1981, 214, 395-400. (b) Schetter, B.; Mahrwald, R. Modern aldol methods for the total synthesis of polyketides. Angew. Chem., Int. Ed. 2006, 45, 7506-7525.

(4) Turks, M.; Laclef, S.; Vogel, P. Construction of Polypropionate Fragments in Natural Product Synthesis. In Stereoselective Synthesis of Drugs and Natural Products; Andrushko, V., Andrushko, N. Eds.; John Wiley \& Sons Inc, 2013; p 271.

(5) (a) Evans, D. A.; Bartroli, J.; Shih, T. L. Enantioselective Aldol Condensations 0.2. Erythro-Selective Chiral Aldol Condensations Via Boron Enolates. J. Am. Chem. Soc. 1981, 103, 2127-2129. (b) Oppolzer, W.; Blagg, J.; Rodriguez, I.; Walther, E. Bornane Sultam-Directed Asymmetric Synthesis of Crystalline, Enantiomerically Pure Syn Aldols. J. Am. Chem. Soc. 1990, 112, 2767-2772. (c) Crimmins, M. T.; King, B. W.; Tabet, E. A.; Chaudhary, K. Asymmetric aldol additions: use of titanium tetrachloride and (-)-sparteine for the soft enolization of $\mathrm{N}$-acyl oxazolidinones, oxazolidinethiones, and thiazolidinethiones. J. Org. Chem. 2001, 66, 894-902. (d) Abiko, A.; Liu, J. F.; Masamune, S. The anti-Selective Boron-Mediated Asymmetric Aldol Reaction of Carboxylic Esters. J. Am. Chem. Soc. 1997, 119, 2586-2587.

(6) (a) Brown, H. C.; Bhat, K. S. Enantiomeric (Z)- and (E)Crotyldiisopinocampheylboranes. Synthesis in High Optical Purity of All Four possible Stereoisomers of $\beta$-Methylhomoallyl Alcohols. J. Am. Chem. Soc. 1986, 108, 293-294. (b) Brown, H. C.; Bhat, K. S. Chiral Synthesis via Organoboranes. 7. Diastereoselective and Enantioselective Synthesis of erythro- and threo- $\beta$-Methylhomoallyl Alcohols via Enantiomeric $(Z)$ - and $(E)$-Crotylboranes. J. Am. Chem. Soc. 1986, 108, 5919-5923. (c) Roush, W. R.; Ando, K.; Powers, D. B.; Palkowitz, A. D.; Halterman, R. L. Asymmetric-Synthesis Using Diisopropyl Tartrate Modified (E)-Crotylboronates and (Z)Crotylboronates - Preparation of the Chiral Crotylboronates and
Reactions with Achiral Aldehydes. J. Am. Chem. Soc. 1990, 112, 6339-6348. (d) Kim, H.; Ho, S.; Leighton, J. L. A More Comprehensive and Highly Practical Solution to Enantioselective Aldehyde Crotylation. J. Am. Chem. Soc. 2011, 133, 6517-6520.

(7) (a) Zbieg, J. R.; Yamaguchi, E.; McInturff, E. L.; Krische, M. J. Enantioselective C-H crotylation of primary alcohols via hydrohydroxyalkylation of butadiene. Science 2012, 336, 324-327. (b) Kim, I. S.; Han, S. B.; Krische, M. J. anti-Diastereo- and Enantioselective Carbonyl Crotylation from the Alcohol or Aldehyde Oxidation Level Employing a Cyclometallated Iridium Catalyst: $\alpha$-Methyl Allyl Acetate as a Surrogate to Preformed Crotylmetal Reagents. J. Am. Chem. Soc. 2009, 131, 2514-2520. (c) McInturff, E. L.; Yamaguchi, E.; Krische, M. J. Chiral-Anion-Dependent Inversion of Diastereoand Enantioselectivity in Carbonyl Crotylation via RutheniumCatalyzed Butadiene Hydrohydroxyalkylation. J. Am. Chem. Soc. 2012, 134, 20628-20631.

(8) (a) Northrup, A. B.; MacMillan, D. W. The First Direct and Enantioselective Cross-Aldol Reaction of Aldehydes. J. Am. Chem. Soc. 2002, 124, 6798-6799. (b) Kano, T.; Yamaguchi, Y.; Tanaka, Y.; Maruoka, K. syn-Selective and enantioselective direct cross-aldol reactions between aldehydes catalyzed by an axially chiral amino sulfonamide. Angew. Chem., Int. Ed. 2007, 46, 1738-1740. (c) Pihko, P. M.; Erkkilä, A. Enantioselective synthesis of prelactone B using a proline-catalyzed crossed-aldol reaction. Tetrahedron Lett. 2003, 44, $7607-7609$.

(9) (a) Mukaiyama, T.; Narasaka, K.; Banno, K. New aldol type reaction. Chem. Lett. 1973, 2, 1011-1014. For reviews on Mukaiyama aldol reaction see: (b) Matsuo, J.-I.; Murakami, M. The Mukaiyama aldol reaction: 40 years of continuous development. Angew. Chem., Int. Ed. 2013, 52, 9109-9118. (c) Kan, S. B.; Ng, K. K.; Paterson, I. The impact of the Mukaiyama aldol reaction in total synthesis. Angew. Chem., Int. Ed. 2013, 52, 9097-9108.

(10) Trost, B. M. The atom economy-a search for synthetic efficiency. Science 1991, 254, 1471-1477.

(11) Burns, N. Z.; Baran, P. S.; Hoffmann, R. W. Redox economy in organic synthesis. Angew. Chem., Int. Ed. 2009, 48, 2854-2867.

(12) Wender, P. A.; Miller, B. L. Synthesis at the molecular frontier. Nature 2009, 460, 197-201.

(13) (a) Boxer, M. B.; Yamamoto, H. Tris(trimethylsilyl)silylGoverned Aldehyde Cross-Aldol Cascade Reaction. J. Am. Chem. Soc. 2006, 128, 48-49. (b) Brady, P. B.; Yamamoto, H. Rapid and Stereochemically Flexible Synthesis of Polypropionates: Super-SilylGoverned Aldol Cascades. Angew. Chem., Int. Ed. 2012, 51, 19421946. (c) Gati, W.; Yamamoto, H. Second generation of aldol reaction. Acc. Chem. Res. 2016, 49, 1757-1768.

(14) Denmark, S. E.; Ghosh, S. K. The First Catalytic, Diastereoselective, and Enantioselective Crossed-Aldol Reactions of Aldehydes. Angew. Chem., Int. Ed. 2001, 40, 4759-4762.

(15) Lin, L.; Yamamoto, K.; Mitsunuma, H.; Kanzaki, Y.; Matsunaga, S.; Kanai, M. Catalytic asymmetric iterative/domino aldehyde cross-aldol reactions for the rapid and flexible synthesis of 1 , 3-polyols. J. Am. Chem. Soc. 2015, 137, 15418-15421.

(16) Schreyer, L.; Kaib, P. S. J.; Wakchaure, V. N.; Obradors, C.; Properzi, R.; Lee, S.; List, B. Confined acids catalyze asymmetric single aldolizations of acetaldehyde enolates. Science 2018, 362, 216219.

(17) Dell'Amico, L.; Zanardi, F. Acetaldehyde silyl enol ethers in enantioselective Mukaiyama aldol reactions: enzyme-like organocatalysis in action. Angew. Chem., Int. Ed. 2019, 58, 3264-3266.

(18) Bae, H. Y.; Höfler, D.; Kaib, P. S.; Kasaplar, P.; De, C. K.; Döhring, A.; Lee, S.; Kaupmees, K.; Leito, I.; List, B. Approaching sub-ppm-level asymmetric organocatalysis of a highly challenging and scalable carbon-carbon bond forming reaction. Nat. Chem. 2018, 10, 888-894.

(19) Krautwald, S.; Carreira, E. M. Stereodivergence in Asymmetric Catalysis. J. Am. Chem. Soc. 2017, 139, 5627-5639.

(20) (a) Kaib, P. S. J.; Schreyer, L.; Lee, S.; Properzi, R.; List, B. Extremely Active Organocatalysts Enable a Highly Enantioselective Addition of Allyltrimethylsilane to Aldehydes. Angew. Chem., Int. Ed. 
2016, 55, 13200-13203. (b) Schreyer, L.; Properzi, R.; List, B. IDPi Catalysis. Angew. Chem., Int. Ed. 2019, 58, 12761-12777.

(21) (a) García-García, P.; Lay, F.; García-García, P.; Rabalakos, C.; List, B. A Powerful Chiral Counteranion Motif for Asymmetric Catalysis. Angew. Chem., Int. Ed. 2009, 48, 4363-4366. (b) James, T.; van Gemmeren, M.; List, B. Development and Applications of Disulfonimides in Enantioselective Organocatalysis. Chem. Rev. 2015, 115, 9388-9409.

(22) (a) Gatzenmeier, T.; Kaib, P. S.; Lingnau, J. B.; Goddard, R.; List, B. The Catalytic Asymmetric Mukaiyama- Michael Reaction of Silyl Ketene Acetals with $\alpha, \beta$-Unsaturated Methyl Esters. Angew. Chem., Int. Ed. 2018, 57, 2464-2468. (b) Gatzenmeier, T.; Turberg, M.; Yepes, D.; Xie, Y.; Neese, F.; Bistoni, G.; List, B. Scalable and highly diastereo- and enantioselective catalytic Diels-Alder reaction of $\alpha, \beta$-unsaturated methyl esters. J. Am. Chem. Soc. 2018, 140, 12671-12676. (c) Zhou, H.; Bae, H. Y.; Leutzsch, M.; Kennemur, J. L.; Bécart, D.; List, B. The Silicon-Hydrogen Exchange Reaction: A Catalytic $\sigma$-Bond Metathesis Approach to the Enantioselective Synthesis of Enol Silanes. J. Am. Chem. Soc. 2020, 142, 1369513700. (d) Zhu, C.; Mandrelli, F.; Zhou, H.; Maji, R.; List, B. Catalytic Asymmetric Synthesis of Unprotected $\beta^{2}$-Amino Acids. J. Am. Chem. Soc. 2021, 143, 3312-3317.

(23) Properzi, R.; Kaib, P. S. J.; Leutzsch, M.; Pupo, G.; Mitra, R.; De, C. K.; Song, L.; Schreiner, P. R.; List, B. Catalytic enantiocontrol over a non-classical carbocation. Nat. Chem. 2020, 12, 1174-1179.

(24) (a) Erickson, J. A.; McLoughlin, J. I. Hydrogen bond donor properties of the difluoromethyl group. J. Org. Chem. 1995, 60, 16261631. (b) Sessler, C. D.; Rahm, M.; Becker, S.; Goldberg, J. M.; Wang, F.; Lippard, S. J. $\mathrm{CF}_{2} \mathrm{H}$, a hydrogen bond donor. J. Am. Chem. Soc. 2017, 139, 9325-9332. (c) Zafrani, Y.; Yeffet, D.; Sod-Moriah, G.; Berliner, A.; Amir, D.; Marciano, D.; Gershonov, E.; Saphier, S. Difluoromethyl bioisostere: examining the "lipophilic hydrogen bond donor" concept. J. Med. Chem. 2017, 60, 797-804.

(25) For polyketides having these substructures see: (a) Lu, S.; Nishimura, S.; Takenaka, K.; Ito, M.; Kato, T.; Kakeya, H. Discovery of Presaccharothriolide X, a Retro-Michael Reaction Product of Saccharothriolide B, from the Rare Actinomycete Saccharothrix sp. A1506. Org. Lett. 2018, 20, 4406-4410. (b) Pimentel-Elardo, S. M.; Gulder, T. A. M.; Hentschel, U.; Bringmann, G. Cebulactams A1 and A2, new macrolactams isolated from Saccharopolyspora cebuensis, the first obligate marine strain of the genus Saccharopolyspora. Tetrahedron Lett. 2008, 49, 6889-6892. (c) Singh, S. B.; Zink, D. L.; Heimbach, B.; Genilloud, O.; Teran, A.; Silverman, K. C.; Lingham, R. B.; Felock, P.; Hazuda, D. Structure, Stereochemistry, and Biological Activity of Integramycin, a Novel Hexacyclic Natural Product Produced by Actinoplanes sp. that Inhibits HIV-1 Integrase. Org. Lett. 2002, 4, 1123-1126.

(26) For a review on the synthesis of ansamycin polyketides see: (a) Wrona, I. E.; Agouridas, V.; Panek, J. S. C. R. Design and synthesis of ansamycin antibiotics. C. R. Chim. 2008, 11, 1483-1522.

(27) Nuhant, P.; Allais, C.; Roush, W. R. DiisopinocampheylboraneMediated Reductive Aldol Reactions: Highly Enantio- and Diastereoselective Synthesis of syn Aldols from N-Acryloylmorpholine. Angew. Chem., Int. Ed. 2013, 52, 8703-8707.

(28) Saito, S.; Fujimaki, T.; Panbangred, W.; Igarashi, Y.; Imoto, M. Antarlides: A New Type of Androgen Receptor (AR) Antagonist that Overcomes Resistance to AR-Targeted Therapy. Angew. Chem., Int. Ed. 2016, 55, 2728-2732.

(29) Poock, C.; Kalesse, M. Total Synthesis of Nannocystin Ax. Org. Lett. 2017, 19, 4536-4539.

(30) Mitschke, B.; Turberg, M.; List, B. Confinement as a Unifying Element in Selective Catalysis. Chem. 2020, 6, 2515-2532.

(31) Takahashi, O.; Kohno, Y.; Nishio, M. Relevance of weak hydrogen bonds in the conformation of organic compounds and bioconjugates: evidence from recent experimental data and high-level ab initio MO calculations. Chem. Rev. 2010, 110, 6049-6076.

(32) The importance of such weak interactions is also manifested when aliphatic aldehydes were used, which gave diminished yet promising enantioselectivities $(70-79 \%$ ee $)$. We are further optimizing our catalysts for aliphatic aldehydes, and results will be published separately. 